\title{
Distinct prognostic values of alcohol dehydrogenase mRNA expression in pancreatic adenocarcinoma
}

\author{
Xiwen Liaol,* \\ Rui Huang ${ }^{2, *}$ \\ Xiaoguang Liu'1,3 \\ Chuangye Han' \\ Long $\mathrm{Yu}^{1,4}$ \\ Shijun Wang ${ }^{5}$ \\ $\mathrm{Na} \mathrm{Sun}{ }^{2}$ \\ Bopei $\mathrm{Li}^{6}$ \\ Xin Ning ${ }^{7}$ \\ Tao Peng' \\ 'Department of Hepatobiliary Surgery, \\ ${ }^{2}$ Department of Hematology, The \\ First Affiliated Hospital of Guangxi \\ Medical University, Nanning, Guangxi, \\ ${ }^{3}$ Department of Hepatobiliary \\ Surgery, Affiliated Hospital of \\ Guangdong Medical University, \\ Zhanjiang, Guangdong, ${ }^{4}$ Department \\ of Hepatobiliary and Pancreatic \\ Surgery, ${ }^{5}$ Department of Colorectal \\ and Anal Surgery, The First Affiliated \\ Hospital of Zhengzhou University, \\ Zhengzhou, Henan, ${ }^{6}$ Department \\ of Gastrointestinal Surgery, \\ ${ }^{7}$ Department of Urology, The First \\ Affiliated Hospital of Guangxi Medical \\ University, Nanning, Guangxi, China \\ *These authors contributed equally \\ to this work
}

This article was published in the following Dove Press journal:

OncoTargets and Therapy

24 July 2017

Number of times this article has been viewed

Background: Alcohol dehydrogenase (ADH) isoenzymes have been reported as a potential diagnostic marker for pancreatic cancer, but their prognostic value in pancreatic cancer remains unclear. The aim of this investigation was to identify the prognostic value of ADH genes in human patients with pancreatic adenocarcinoma (PAAD).

Materials and methods: An RNA sequencing dataset and corresponding survival profiles of PAAD were obtained from The Cancer Genome Atlas. Survival analysis and gene set enrichment analysis were used to investigate the prediction value and potential mechanism of ADH genes in PAAD prognosis.

Results: Survival analysis of ADH genes suggests that a high expression of $A D H 1 A$ (adjusted $P=0.037$, adjusted hazard ratio $[\mathrm{HR}]=0.627,95 \% \mathrm{CI}=0.404-0.972$ ) and $A D H 6$ (adjusted $P=0.018$, adjusted $\mathrm{HR}=0.588,95 \% \mathrm{CI}=0.378-0.914$ ) were associated with a significantly decreased risk of death, while a high expression of $A D H 5$ was associated with a significantly increased risk of death (adjusted $P=0.043$, adjusted $\mathrm{HR}=1.564,95 \% \mathrm{CI}=1.013-2.414$ ). Joint effects analysis of three $\mathrm{ADH}$ gene prognostic markers suggests that the prognosis difference for any marker combination was more significant than that for any individual marker. The potential mechanism of $A D H 1 A$ and $A D H 6$ in PAAD prognosis was that a high expression of $A D H 1 A$ and $A D H 6$ was involved in the $\mathrm{P} 450$ pathway and biological processes, while high $A D H 5$ expression was involved in transforming growth factor $\beta$ regulation-related pathways and biological processes, Wnt, the cell cycle, ErbB, and mitogen-activated protein kinase signaling pathways.

Conclusion: Our data suggest that $A D H 1 A, A D H 5$, and $A D H 6$ expression may be potential prognostic markers of PAAD and in combination have a strong interaction and better predictive value for PAAD prognosis.

Keywords: prognostic, alcohol dehydrogenase, pancreatic adenocarcinoma, TCGA, GSEA

\section{Introduction}

Pancreatic cancer presents as highly lethal malignant tumors, for which mortality closely parallels incidence, with an estimated 330,400 deaths occurring worldwide in 2012. ${ }^{1,2}$ It is estimated that about 79,400 Chinese will die from pancreatic cancer in 2015 , and it is predicted that there will be about 90,100 newly diagnosed pancreatic cancer cases in China in $2015 .^{3}$ The age-standardized mortality rates of pancreatic cancer in the Chinese male population have been shown to have an upward trend. ${ }^{3}$ Pancreatic cancer patients always have a relatively poor prognosis in China with an age-standardized 5-year relative survival rate of $11.7 \%{ }^{4}$ Therefore, it is very important to find markers and prognostic predictive indicators that detect malignant cell transformation at an early stage.

Correspondence: Tao Peng

Department of Hepatobiliary Surgery,

The First Affiliated Hospital of Guangxi

Medical University, 6 Shuang Yong

Road, Nanning 53002I, Guangxi Zhuang

Autonomous Region, China

Tel +86 77I 5350190

Fax +86 77। 535003 I

Email pengtaogmu@।63.com 
Studies have demonstrated that alcohol dehydrogenase $(\mathrm{ADH})$ is present in the pancreatic tissue and plays an important role in multiple biological processes of the pancreas. ${ }^{5,6}$ A study by Jelski et al reported that class III ADH activity was markedly higher in pancreatic cancer tissue than in healthy tissue. ${ }^{7} \mathrm{ADH}$ isoenzymes have also been reported as a potential diagnostic marker for pancreatic cancer, and the combination of circulating ADH and macrophage inhibitory cytokine to carbohydrate antigen 19-9 can improve the overall quality of diagnosis for this lethal disease. ${ }^{8,9}$ Although the diagnostic value of $\mathrm{ADH}$ in pancreatic cancer has been identified, the prognostic value of $\mathrm{ADH}$ in pancreatic cancer remains unclear. The aim of this investigation was to identify the prognostic value of ADH gene expression in pancreatic cancer patients.

The Cancer Genome Atlas (TCGA) has generated comprehensive, multidimensional maps of the key genomic changes in 33 types of cancer including pancreatic adenocarcinoma (PAAD), which is available as open access. In the present study, we utilized the TCGA database to investigate the prognostic prediction value and potential mechanism of ADH genes in patients with PAAD.

\section{Materials and methods}

\section{RNA sequencing dataset}

An RNA sequencing dataset including 177 PAAD patient transcriptome and corresponding survival profiles was obtained from the TCGA web server (https://portal.gdc.cancer.gov/, accessed March 20, 2017). RNA sequencing datasets of 177 tumor tissues and four adjacent normal tissues were downloaded from the TCGA database; information on overall survival (OS), as well as the status of events, was available for all of these patients. Normalization of the PAAD RNA sequencing dataset was performed using DESeq, an $R$ package for transcriptome profiling, according to the user guide. ${ }^{10}$ Genes that were 0 in $>10 \%$ of all subjects were eliminated.

\section{Association analysis}

The comparison of ADH gene expression between pancreatic tumor tissue and adjacent normal tissues was done by an analysis using Metabolic gEne RApid Visualizer ${ }^{11}$ (http://merav.wi.mit.edu/) and TCGA dataset, respectively. Pearson correlation coefficient was used to evaluate correlations among genes in coexpression analysis.

\section{Survival analysis}

All patients were divided into two groups according to gene expression levels in tumor tissue for survival analysis.
The high-expression group consisted of patients in which gene expression levels were above the median value, and a low-expression group comprised the remaining patients. We also stratified the analysis on the basis of associations between gene expression and clinical features in OS. Alcohol history and tumor stage were adjusted in multivariate Cox proportion hazard regression analysis. On the basis of the results of coexpression analysis, we also investigated the joint effects of significant prognostic-related $\mathrm{ADH}$ genes in PAAD.

\section{Gene set enrichment analysis}

Differences of pathways and biological process in transcriptome levels between high and low ADH genes expression were analyzed using gene set enrichment analysis (GSEA) v2-2.2.3, ${ }^{12,13}$ with reference to gene sets from the Molecular Signatures Database (MSigDB) of c2 (KEGG gene sets: c2.cp.kegg.v5.2.symbols.gmt) and c5 (GO gene sets: c5.bp. v5.2.symbols.gmt, c5.cc.v5.2.symbols.gmt, and c5.mf. v5.2.symbols.gmt), respectively. The number of permutations was set at 1,000. Enrichment results satisfying a nominal $P$-value $<0.05$ and a false discovery rate $(\mathrm{FDR})<0.25$ were considered statistically significant.

\section{Statistical analysis}

The mRNA expression of ADH genes in tumor and adjacent nontumor tissue was analyzed using an independent sample $t$-test. The Pearson correlation coefficient was used to assess the coexpression correlation at the mRNA level, and the coexpression heat map was constructed by the corrplot package in the $R$ platform. Survival analysis was carried out using the Kaplan-Meier method with the log-rank test to compare clinical factors and gene expression groups. Cox proportional hazards regression analysis was used to calculate the crude or adjusted hazard ratio (HR) and 95\% $\mathrm{CI}$ in uni- and multivariate analyses. The FDR in GSEA was adjusted for multiple testing with the BenjaminiHochberg procedure to control FDR. ${ }^{14,15}$ Kaplan-Meier survival curves were plotted using GraphPad Prism 6.0. A value of $P<0.05$ was considered statistically significant. Data were analyzed with the help of SPSS v.20.0 software (IBM, Chicago, IL, USA).

\section{Results}

\section{Data processing}

Seven ADH genes were available in the TCGA PAAD mRNA expression dataset, $A D H 1 A, A D H 1 B, A D H 1 C$, $A D H 4, A D H 5, A D H 6$, and $A D H 7$. After normalization of the RNA sequencing data, we found that the expression level 
of $A D H 7$ was very low in PAAD tumor tissue. Therefore, $A D H 7$ data were excluded from the present study. After normalization by DESeq, 177 pancreatic tumor tissues and 4 adjacent normal tissues expression data with six ADH genes were used for further analysis.

\section{Association analysis}

Distribution of ADH gene expression between pancreatic tumor tissue and adjacent normal tissues using MERAV (Figure $1 \mathrm{~A}-\mathrm{F}$ ) showed that $A D H 1 A$ and $A D H 1 B$ were markedly downregulated in pancreatic tumor tissue (Figure $1 \mathrm{~A}$ and $\mathrm{B}$ ), whereas $A D H 5$ was significantly upregulated in tumor tissue (Figure 1E). Similar results were also observed in $A D H 1 B$ and $A D H 5$ of patients with TCGA PAAD (Figure 2A), but the difference did not reach statistical significance among these genes. Coexpression analysis of ADH genes indicated that $A D H 1 A(r=0.581, P<0.001$, Figure $2 \mathrm{~B})$, $A D H 1 C$ ( $r=0.371, P<0.001$, Figure 2B), and $A D H 6(r=0.502$, $P<0.001$, Figure $2 \mathrm{~B}$ ) had a significantly positive correlation with $A D H 4$ in PAAD tumor tissue, while $A D H 1 A$ ( $r=0.761$, $P<0.001$, Figure 2B) and $A D H 5$ ( $r=0.176, P=0.019$, Figure 2B) had a significantly positive correlation with $A D H 6$.

\section{Survival analysis}

The clinical characteristics of PAAD are summarized in Table 1. Information only with regard to age, sex, alcohol history, tumor stage, and clinical outcomes of the PAAD can be obtained from the TCGA website. OS stratified by the clinical characteristics indicate that advanced tumor stage was associated with a significantly increased risk of death in PAAD patients. Survival analysis of ADH genes are showed in Figure $3 \mathrm{~A}-\mathrm{F}$, and suggested that a high expression
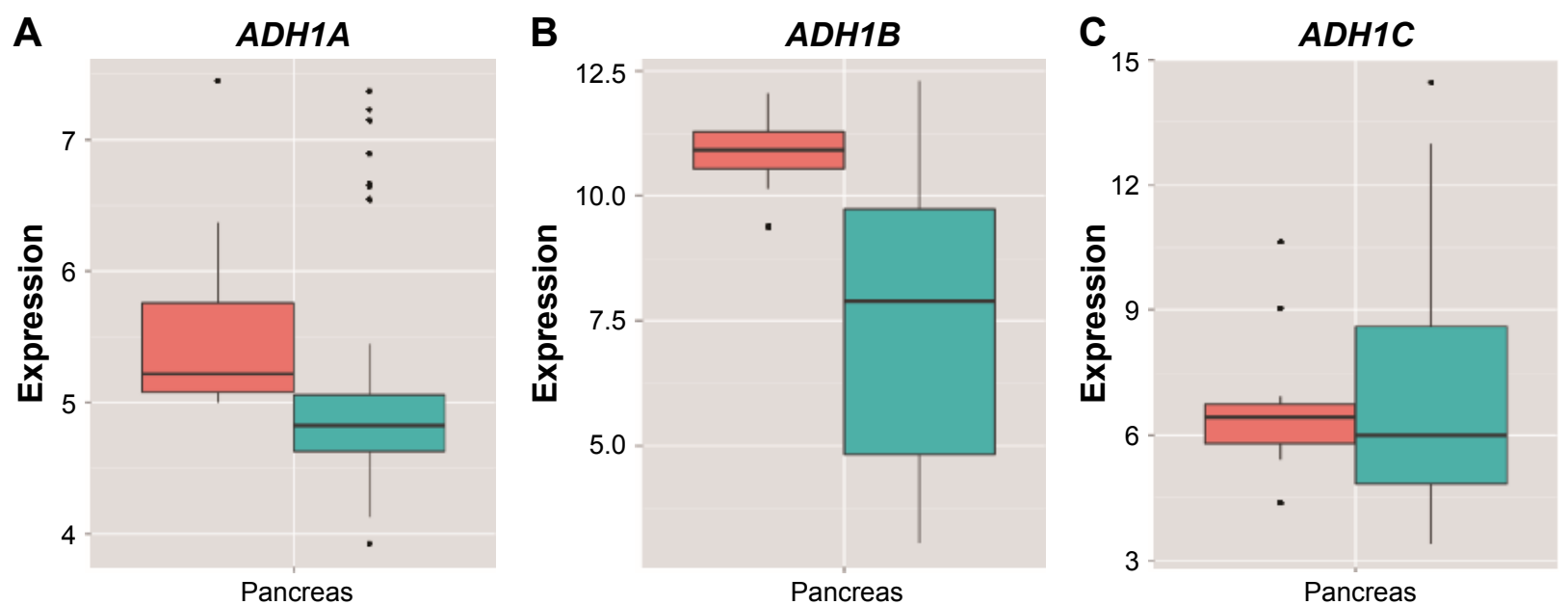

D

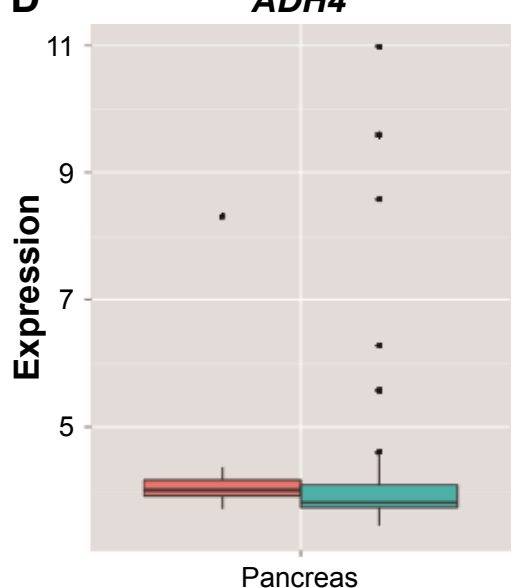

E

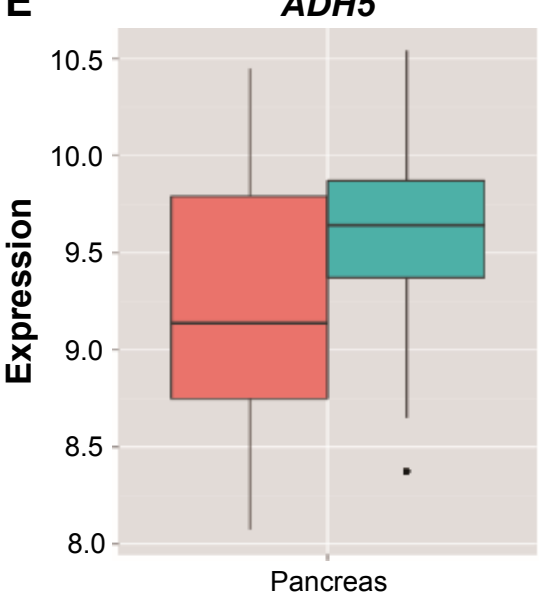

$\mathbf{F}$

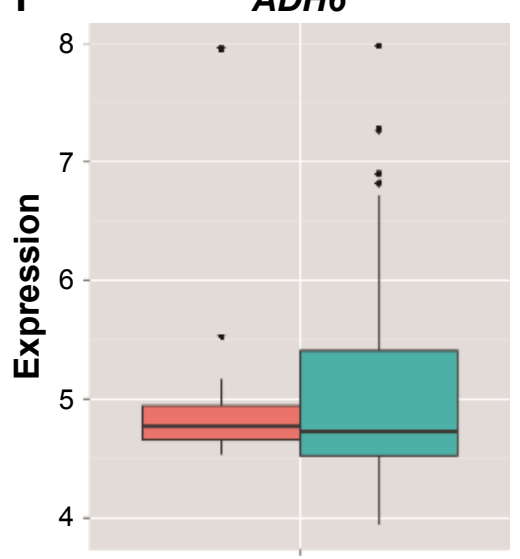

Pancreas

Tissue

帛 Normal tissue 官 Primary tumor

Figure I Distribution of ADH genes expression between pancreatic tumor tissue and adjacent normal tissues using the MERAV web server.

Notes: The order in (A-F) shows the distribution of $A D H I A, A D H I B, A D H I C, A D H 4, A D H 5$, and $A D H 6$ gene mRNA expression between pancreatic tumor tissue and adjacent normal tissues, respectively.

Abbreviations: ADH, alcohol dehydrogenase; MERAV, metabolic gEne RApid visualizer. 

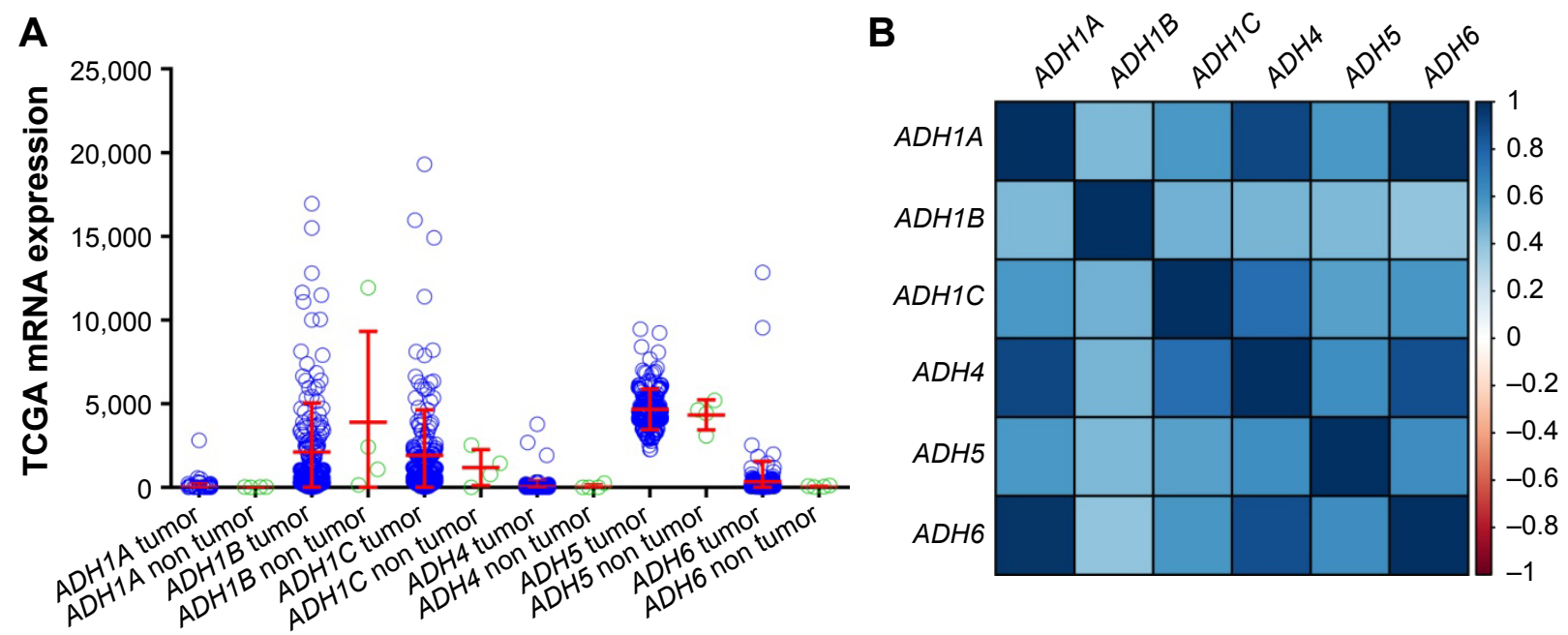

Figure 2 Gene expression distribution and coexpression heat map of ADH genes using the TCGA dataset.

Notes: (A) Distribution of $\mathrm{ADH}$ genes expression between the tumor tissue and adjacent normal tissues; (B) coexpression heat map of ADH genes in PAAD tumor tissue.

Abbreviations: ADH, alcohol dehydrogenase; TCGA, The Cancer Genome Atlas; PAAD, pancreatic adenocarcinoma.

of $A D H 1 A$ (adjusted $P=0.037$, adjusted $\mathrm{HR}=0.627,95 \%$ $\mathrm{CI}=0.404-0.972$; Table 2 ) and $A D H 6$ (adjusted $P=0.018$, adjusted $\mathrm{HR}=0.588,95 \% \mathrm{CI}=0.378-0.914$; Table 2 ) was significantly associated with a decreased risk of death and a long median survival time (MST; 545 vs 913 days for low $A D H 1 A$ vs high $A D H 1 A$, log-rank $P=0.073$, Figure $3 \mathrm{~A}$; 592 vs 691 days for low $A D H 6$ vs high $A D H 6$, log-rank $P=0.03$, Figure $3 \mathrm{C}$; respectively) in PAAD patients, after adjusting for alcohol history and tumor stage. In contrast, a high expression of $A D H 5$ was significantly associated with a poor clinical outcome (MST: 702 vs 511 days for low $A D H 5$ vs high $A D H 5$, log-rank $P=0.0079$, Figure $3 \mathrm{~B}$ )

Table I Clinical characteristics of PAAD patients

\begin{tabular}{|c|c|c|c|c|}
\hline Variables & Events/total & $\begin{array}{l}\text { MST } \\
\text { (days) }\end{array}$ & $\begin{array}{l}\text { Crude HR } \\
(95 \% \mathrm{Cl})\end{array}$ & $\begin{array}{l}\text { Log-rank } \\
P \text {-value }\end{array}$ \\
\hline \multicolumn{5}{|l|}{ Age (years) ${ }^{\mathrm{a}}$} \\
\hline$\leq 60$ & $25 / 54$ & 684 & 1 & \\
\hline$>60$ & $67 / 123$ & 598 & $\mathrm{I} .42 \mathrm{I}(0.897-2.25 \mathrm{I})$ & 0.132 \\
\hline \multicolumn{5}{|l|}{ Sex } \\
\hline Male & $46 / 97$ & 661 & 1 & \\
\hline Female & $46 / 80$ & 568 & $1.219(0.809-1.836)$ & 0.343 \\
\hline \multicolumn{5}{|c|}{ Alcohol history ${ }^{\mathrm{b}}$} \\
\hline No & $32 / 64$ & 607 & 1 & \\
\hline Yes & $52 / 101$ & 603 & I.I $26(0.724-1.749)$ & 0.599 \\
\hline \multicolumn{5}{|c|}{ Tumor stage } \\
\hline I & $7 / 21$ & NA & I & \\
\hline II & $82 / 146$ & 596 & $2.333(1.069-5.089)$ & 0.033 \\
\hline III+IV & $3 / 7$ & 545 & $1.715(0.438-6.719)$ & 0.439 \\
\hline
\end{tabular}

Notes: ${ }^{a}$ Age at initial pathologic diagnosis; binformation of alcohol history was unavailable in 12 patients; cinformation of tumor stage was unavailable in 3 patients. Abbreviations: HR, hazard ratio; MST, median survival time; PAAD, pancreatic adenocarcinoma; NA, not available. and an increased risk of death (adjusted $P=0.043$, adjusted $\mathrm{HR}=1.564,95 \% \mathrm{CI}=1.013-2.414$; Table 2). The associations between other ADH genes and PAAD OS did not show statistical significance.

\section{Stratification analysis}

Results of the stratified analysis of $A D H 1 A, A D H 5$, and $A D H 6$ with OS in different strata of clinical characteristics are shown in Table 3. A high expression of $A D H 1 A$ (adjusted $P=0.017$, adjusted $\mathrm{HR}=0.468,95 \% \mathrm{CI}=0.251-0.873)$ and $A D H 6$ (adjusted $P=0.026$, adjusted $\mathrm{HR}=0.498,95 \% \mathrm{CI}=0.270-0.918$ ) has a protective effect in male PAAD patients, while high $A D H 5$ expression significantly increases the risk of death (adjusted $P=0.028$, adjusted $\mathrm{HR}=1.977,95 \% \mathrm{CI}=1.075-3.636$ ). Similar protective effects can also be found with age $>60$ years (adjusted $P=0.006$, adjusted $\mathrm{HR}=0.488,95 \% \mathrm{CI}=0.293-0.811$ ) and tumor stage II (adjusted $P=0.049$, adjusted $\mathrm{HR}=0.627$, $95 \% \mathrm{CI}=0.394-0.997$ ) in patients with high $A D H 6$ expression. However, high $A D H 5$ expression also increased the risk of death in patients without a history of alcohol (adjusted $P=0.014$, adjusted $\mathrm{HR}=2.574,95 \% \mathrm{CI}=1.213-5.464)$.

\section{Joint effects analysis}

Coexpression analysis indicates that $A D H 1 A$ and $A D H 5$ were positively correlated with $A D H 6$ at the mRNA expression level. We further investigated the joint effects of these genes in the prediction of PAAD prognosis. The combination of $A D H 1 A$ and $A D H 5$ was divided into three groups (Table S1) for assessing the prognostic value in PAAD according to the associations between the genes and OS. Similar 
Table 2 Associations between ADH genes and OS in PAAD patients

\begin{tabular}{|c|c|c|c|c|c|c|}
\hline $\begin{array}{l}\text { Gene } \\
\text { expression }\end{array}$ & Events/total & $\begin{array}{l}\text { MST } \\
\text { (days) }\end{array}$ & $\begin{array}{l}\text { Crude HR } \\
(95 \% \mathrm{Cl})\end{array}$ & $\begin{array}{l}\text { Crude } \\
\text { P-value }\end{array}$ & $\begin{array}{l}\text { Adjusted HR } \\
(95 \% \mathrm{Cl})\end{array}$ & $\begin{array}{l}\text { Adjusted } \\
P_{\text {-value }}{ }^{a}\end{array}$ \\
\hline \multicolumn{7}{|l|}{$\overline{A D H I A}$} \\
\hline Low & $54 / 89$ & 545 & I & & 1 & \\
\hline High & $38 / 88$ & 913 & $0.685(0.452-1.039)$ & 0.075 & $0.627(0.404-0.972)$ & 0.037 \\
\hline \multicolumn{7}{|l|}{$A D H I B$} \\
\hline Low & $51 / 89$ & 598 & I & & 1 & \\
\hline High & $4 I / 88$ & 634 & $0.816(0.540-1.232)$ & 0.333 & $0.858(0.552-1.334)$ & 0.497 \\
\hline \multicolumn{7}{|l|}{$A D H I C$} \\
\hline Low & $44 / 89$ & 634 & 1 & & 1 & \\
\hline High & $48 / 88$ & 592 & $1.265(0.838-1.909)$ & 0.263 & $1.038(0.656-1.64 I)$ & 0.874 \\
\hline \multicolumn{7}{|l|}{$\mathrm{ADH} 4$} \\
\hline Low & $47 / 89$ & 598 & I & & I & \\
\hline High & $45 / 88$ & 652 & $0.98 \mid(0.65 I-I .478)$ & 0.926 & $0.917(0.592-1.421)$ & 0.698 \\
\hline \multicolumn{7}{|l|}{ ADH5 } \\
\hline Low & $40 / 89$ & 702 & I & & 1 & \\
\hline High & $52 / 88$ & 511 & $1.760(1.153-2.685)$ & 0.009 & $1.564(1.013-2.414)$ & 0.043 \\
\hline \multicolumn{7}{|l|}{$A D H 6$} \\
\hline Low & $53 / 89$ & 592 & 1 & & 1 & \\
\hline High & $39 / 88$ & 691 & $0.634(0.419-0.96 I)$ & 0.032 & $0.588(0.378-0.914)$ & 0.018 \\
\hline
\end{tabular}

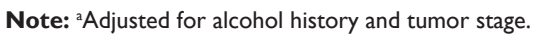

Abbreviations: ADH, alcohol dehydrogenase; HR, hazard ratio; MST, median survival time; OS, overall survival; PAAD, pancreatic adenocarcinoma.

classification methods were also used for the combinations of $A D H 1 A+A D H 6, A D H 5+A D H 6$, and $A D H 1 A+A D H 5+A D H 6$, and the detailed grouping information is shown in Table S1. Joint effects analysis in the combination of $A D H 1 A$ and
$A D H 5$ demonstrated that group 2 (adjusted $P=0.011$, adjusted $\mathrm{HR}=0.525,95 \% \mathrm{CI}=0.320-0.862$, Table 4; Figure 4A) and group 3 (adjusted $P=0.003$, adjusted $\mathrm{HR}=0.379$, 95\% $\mathrm{CI}=0.198-0.723$, Table 4; Figure 4A) were associated with
A
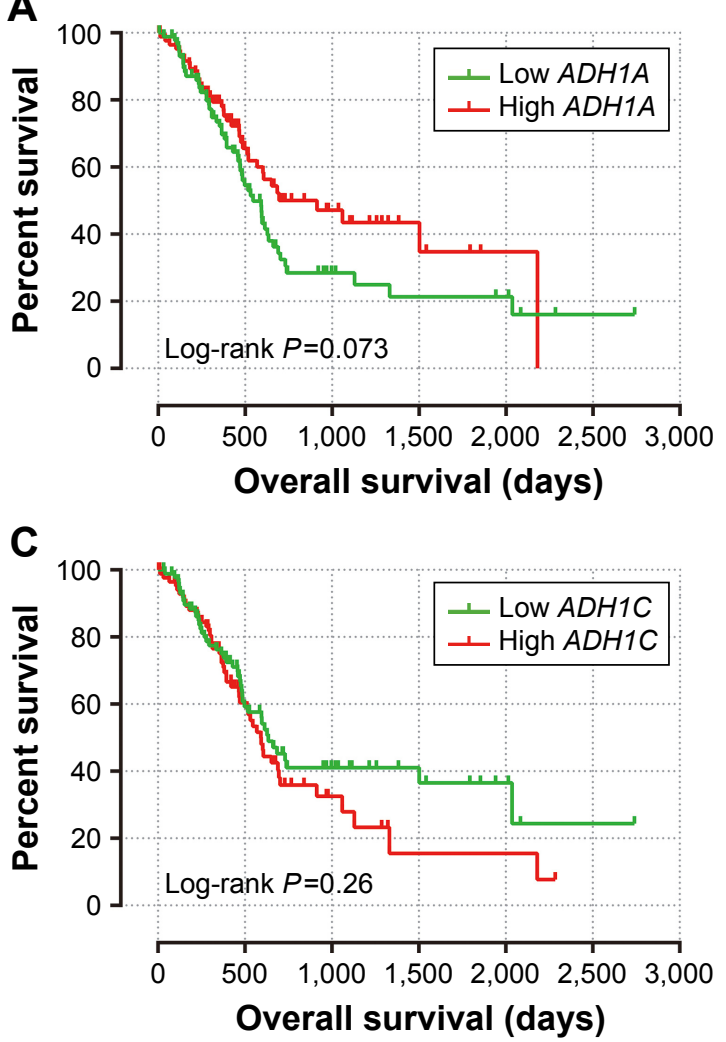

B

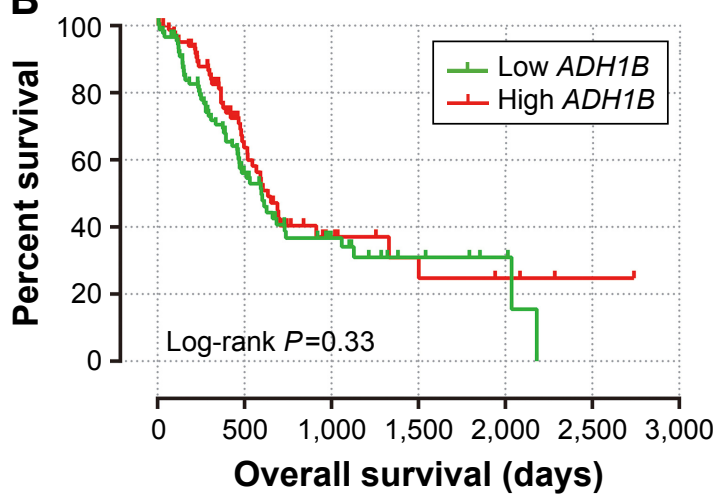

D

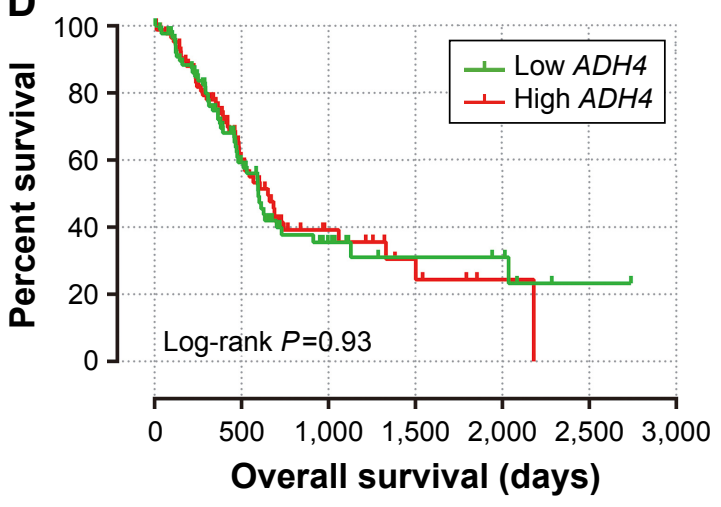

Figure 3 (Continued) 

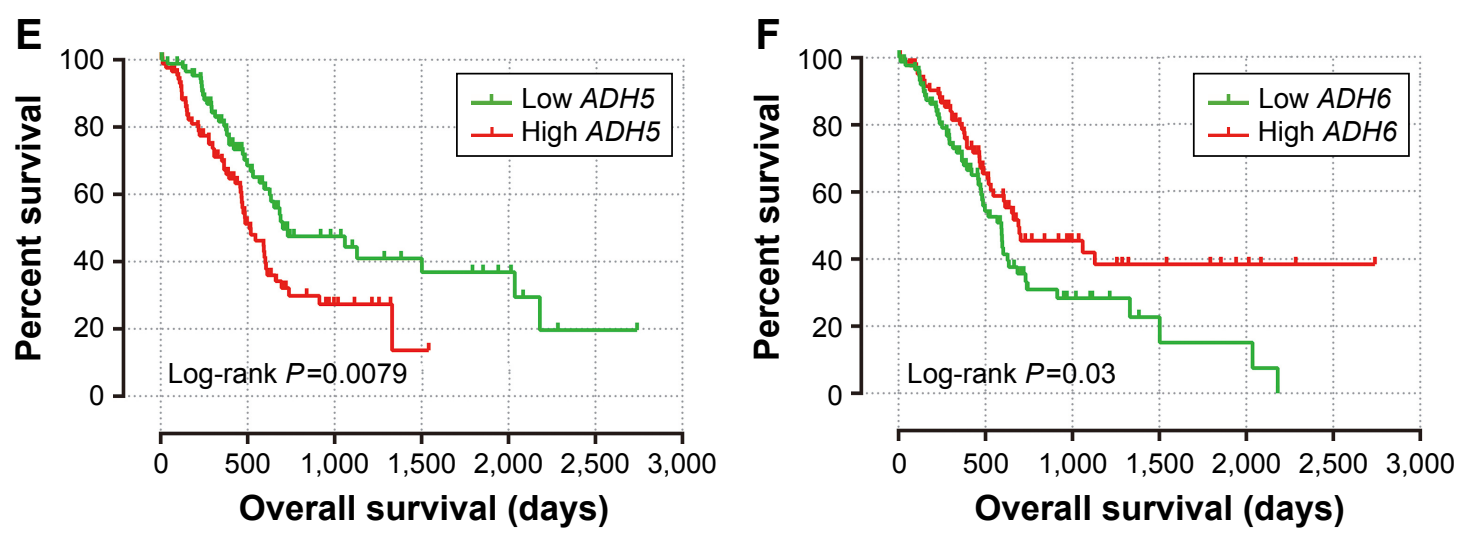

Figure 3 The prognostic value of $A D H$ genes expression in PAAD patients.

Notes: (A) OS stratified by ADHIA; (B) OS stratified by ADHIB; (C) OS stratified by ADHIC; (D) OS stratified by ADH4; (E) OS stratified by ADH5; (F) OS stratified by ADH6. Abbreviations: $A D H$, alcohol dehydrogenase; PAAD, pancreatic adenocarcinoma; OS, overall survival.

a significantly decreased risk of death in PAAD, compared to group 1. In Table 4, a protective effect can also be observed in the combination of $A D H 1 A+A D H 6$ (group ii vs group i, adjusted $P=0.029$, adjusted $\mathrm{HR}=0.576,95 \% \mathrm{CI}=0.351-0.946$; group iii vs group i, adjusted $P=0.003$, adjusted $\mathrm{HR}=0.408$, $95 \% \mathrm{CI}=0.225-0.741$, Figure 4B), $A D H 5+A D H 6$ (group C vs group $\mathrm{A}$, adjusted $P=0.004$, adjusted $\mathrm{HR}=0.378$, 95\% $\mathrm{CI}=0.196-0.727$, Figure $4 \mathrm{C}$ ) and $A D H 1 A+A D H 5+A D H 6$ (group III vs group I, adjusted $P=0.014$, adjusted $H R=0.475$, 95\% CI $=0.262-0.861$; group IV vs group I, adjusted $P=0.003$, adjusted HR $=0.221,95 \% \mathrm{CI}=0.082-0.597$, Figure 4D), respectively. Our joint effects analysis of the three ADH gene prognostic markers suggests that the prognosis difference for any marker combination was more significant than that for any individual marker.

\section{Gene set enrichment analysis}

To further explore the potential mechanism of ADH genes in PAAD prognosis, we used the PAAD genome-wide RNA sequencing dataset for GSEA. GSEA results of the $\mathrm{c} 5$ reference gene set suggest that high $A D H 1 A$ expression was involved in the epoxygenase P450 pathway and cell differentiation regulation biological processes (Figure $5 \mathrm{~A}$ and $\mathrm{B}$; Table $\mathrm{S} 2$ ), while the enrichment of $\mathrm{c} 2$ indicates that high $A D H 1 A$ is also involved in drug metabolism, cytochrome P450, fatty acid metabolism, and peroxisome proliferator-activated receptor signaling pathway (Figure 5C-F; Table S3). GSEA results reveal that the high expression of $A D H 5$ was correlated to the transforming growth factor $\beta$ (TGF- $\beta$ ) regulation-related biological process (Figure 6A-E; Table S4), whereas the c2 enrichments suggest that high $A D H 5$ expression is involved in TGF- $\beta$, Wnt, cell cycle, ErbB, mitogen-activated protein

Table 3 Stratified analysis of ADH genes and OS in PAAD patients

\begin{tabular}{|c|c|c|c|c|c|c|c|c|c|c|c|c|}
\hline \multirow[t]{2}{*}{ Variables } & \multicolumn{4}{|c|}{ ADHIA } & \multicolumn{4}{|c|}{ ADH5 } & \multicolumn{4}{|c|}{ ADH6 } \\
\hline & Low & High & $\begin{array}{l}\text { Adjusted HR } \\
(95 \% \mathrm{Cl})\end{array}$ & $\begin{array}{l}\text { Adjusted } \\
\text {-value }^{\mathrm{a}}\end{array}$ & Low & High & $\begin{array}{l}\text { Adjusted HR } \\
(95 \% \mathrm{Cl})\end{array}$ & $\begin{array}{l}\text { Adjusted } \\
\text {-value }^{\mathrm{a}}\end{array}$ & Low & High & $\begin{array}{l}\text { Adjusted HR } \\
(95 \% \mathrm{Cl})\end{array}$ & $\begin{array}{l}\text { Adjusted } \\
\text {-value }^{\text {a }}\end{array}$ \\
\hline \multicolumn{13}{|c|}{ Age (years) ${ }^{b}$} \\
\hline$\leq 60$ & 23 & 31 & $0.474(0.194-1.155)$ & 0.100 & 25 & 29 & I.52I (0.628-3.683) & 0.352 & 31 & 23 & $0.744(0.292-1.896)$ & 0.535 \\
\hline$>60$ & 66 & 57 & $0.787(0.470-1.317)$ & 0.362 & 64 & 59 & $1.638(0.989-2.7 \mid 3)$ & 0.055 & 58 & 65 & $0.488(0.293-0.81 \mathrm{I})$ & 0.006 \\
\hline \multicolumn{13}{|l|}{ Sex } \\
\hline Male & 46 & 51 & $0.468(0.25 \mathrm{I}-0.873)$ & 0.017 & 54 & 43 & $1.977(1.075-3.636)$ & 0.028 & 45 & 52 & $0.498(0.270-0.918)$ & 0.026 \\
\hline Female & 43 & 37 & $0.919(0.489-1.727)$ & 0.792 & 35 & 45 & $1.039(0.549-1.968)$ & 0.906 & 44 & 36 & $0.806(0.422-1.539)$ & 0.514 \\
\hline \multicolumn{13}{|c|}{ Alcohol history ${ }^{c}$} \\
\hline No & 34 & 30 & $0.677(0.327-1.403)$ & 0.295 & 30 & 34 & $2.574(1.213-5.464)$ & 0.014 & 28 & 36 & $0.617(0.302-1.259)$ & 0.184 \\
\hline Yes & 49 & 52 & $0.598(0.343-1.043)$ & 0.070 & 53 & 48 & I.I47 (0.663-I.984) & 0.624 & 53 & 48 & $0.587(0.333-1.034)$ & 0.065 \\
\hline \multicolumn{13}{|c|}{ Tumor stage $^{d}$} \\
\hline I & 13 & 8 & $0.248(0.030-2.074)$ & 0.198 & 11 & 10 & I.588 (0.352-7.160) & 0.547 & 10 & 11 & $0.444(0.086-2.296)$ & 0.333 \\
\hline$\|$ & 71 & 75 & $0.680(0.428-1.079)$ & 0.101 & 74 & 72 & $\mathrm{I} .583(0.998-2.5 \mathrm{II})$ & 0.051 & 76 & 70 & $0.627(0.394-0.997)$ & 0.049 \\
\hline III+IV & 3 & 4 & $0.33 \mathrm{I}(0.02 \mathrm{I}-5.355)$ & 0.437 & 2 & 5 & I.0 (0.084-II.894) & 1.0 & 2 & 5 & $0.33 \mathrm{I}(0.02 \mathrm{I}-5.355)$ & 0.437 \\
\hline
\end{tabular}

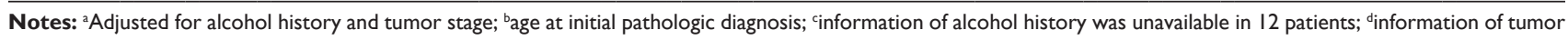
stage was unavailable in 3 patients.

Abbreviations: $A D H$, alcohol dehydrogenase; HR, hazard ratio; MST, median survival time; OS, overall survival; PAAD, pancreatic adenocarcinoma. 
Table 4 Joint effects analysis of ADH genes and OS in PAAD patients

\begin{tabular}{|c|c|c|c|c|c|c|}
\hline Groups & Events/total & MST (days) & $\begin{array}{l}\text { Crude HR } \\
(95 \% \mathrm{Cl})\end{array}$ & $\begin{array}{l}\text { Crude } \\
\text { P-value }\end{array}$ & $\begin{array}{l}\text { Adjusted HR } \\
(95 \% \mathrm{Cl})\end{array}$ & $\begin{array}{l}\text { Adjusted } \\
\text { P-value }^{\mathrm{a}}\end{array}$ \\
\hline \multicolumn{7}{|c|}{$A D H I A+A D H 5$} \\
\hline Group I & $30 / 45$ & 470 & I & & I & \\
\hline Group 2 & $46 / 87$ & 607 & $0.556(0.349-0.887)$ & 0.014 & $0.525(0.320-0.862)$ & 0.011 \\
\hline Group 3 & $16 / 45$ & $\mathrm{I}, 502$ & $0.378(0.205-0.697)$ & 0.002 & $0.379(0.198-0.723)$ & 0.003 \\
\hline \multicolumn{7}{|c|}{$A D H I A+A D H 6$} \\
\hline Group i & $34 / 50$ & 498 & I & & I & \\
\hline Group ii & $39 / 78$ & 661 & $0.592(0.37 I-0.944)$ & 0.028 & $0.576(0.35 \mathrm{I}-0.946)$ & 0.029 \\
\hline Group iii & $19 / 49$ & 1,059 & $0.473(0.269-0.832)$ & 0.009 & $0.408(0.225-0.74 I)$ & 0.003 \\
\hline \multicolumn{7}{|l|}{$A D H 5+A D H 6$} \\
\hline Group A & $27 / 47$ & 592 & 1 & & 1 & \\
\hline Group B & $5 \mathrm{I} / 83$ & 518 & $0.936(0.585-1.496)$ & 0.782 & $0.904(0.552-1.478)$ & 0.687 \\
\hline Group C & $14 / 47$ & NA & $0.339(0.176-0.654)$ & 0.001 & $0.378(0.196-0.727)$ & 0.004 \\
\hline \multicolumn{7}{|c|}{$A D H I A+A D H 5+A D H 6$} \\
\hline Group I & $19 / 29$ & 460 & I & & 1 & \\
\hline Group II & $34 / 55$ & 517 & $0.76 \mid(0.433-1.336)$ & 0.342 & $0.726(0.403-1.308)$ & 0.286 \\
\hline Group III & $34 / 69$ & 691 & $0.503(0.284-0.890)$ & 0.018 & $0.475(0.262-0.86 I)$ & 0.014 \\
\hline Group IV & $5 / 24$ & NA & $0.212(0.079-0.569)$ & 0.002 & $0.22 I(0.082-0.597)$ & 0.003 \\
\hline
\end{tabular}

Notes: Group I: low ADHIA+high ADH5; Group 2: low ADHIA+low ADH5 or high ADHIA+high ADH5; Group 3: high ADHIA+low ADH5; Group i: low ADHIA+low ADH6; Group ii: low $A D H I A+$ high $A D H 6$ or high $A D H I A+l o w ~ A D H 6$; Group iii: high $A D H I A+$ high $A D H 6$; Group A: high $A D H 5$ +low ADH6; Group B: low $A D H 5+$ low $A D H 6$ or high $A D H 5$ +high $A D H 6$; Group C: low ADH5+high ADH6; Group I: low ADHIA+high ADH5+low ADH6; Group Il: low ADHIA+high ADH5+high ADH6 or low ADHIA+low ADH5+ low $A D H 6$ or high $A D H I A+$ tigh $A D H 5+$ low $A D H 6$; Group III: low $A D H I A+$ low $A D H 5$ +high $A D H 6$ or high $A D H I A+$ tigh $A D H 5+$ tigh $A D H 6$ or high $A D H I A+l o w ~ A D H 5+l o w$ ADH6; Group IV: high $A D H I A+$ low $A D H 5$ +high $A D H 6$; ${ }^{\text {a }}$ adjusted for alcohol history and tumor stage.

Abbreviations: ADH, alcohol dehydrogenase; HR, hazard ratio; MST, median survival time; OS, overall survival; PAAD, pancreatic adenocarcinoma; NA, not available.
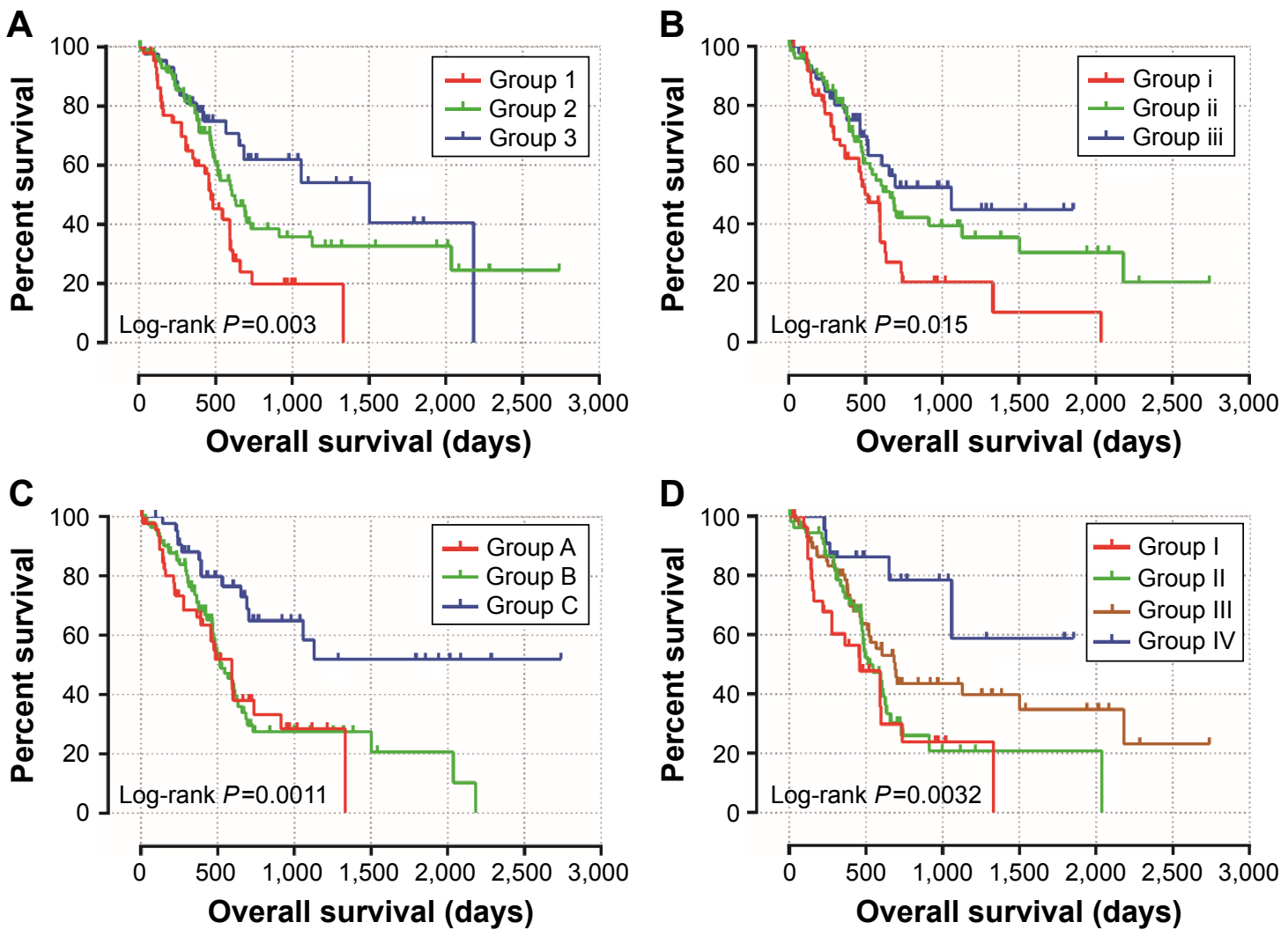

Figure 4 Kaplan-Meier survival curve for joint effects analysis among ADHIA, ADH5, and ADH6 in PAAD patients.

Notes: (A) Joint effects analysis of $A D H I A$ and $A D H 5$; (B) joint effects analysis of $A D H I A$ and $A D H 6$; (C) joint effects analysis of $A D H 5$ and $A D H 6$; (D) joint effects analysis of $A D H I A, A D H 5$, and ADH6.

Abbreviations: ADH, alcohol dehydrogenase; PAAD, pancreatic adenocarcinoma. 

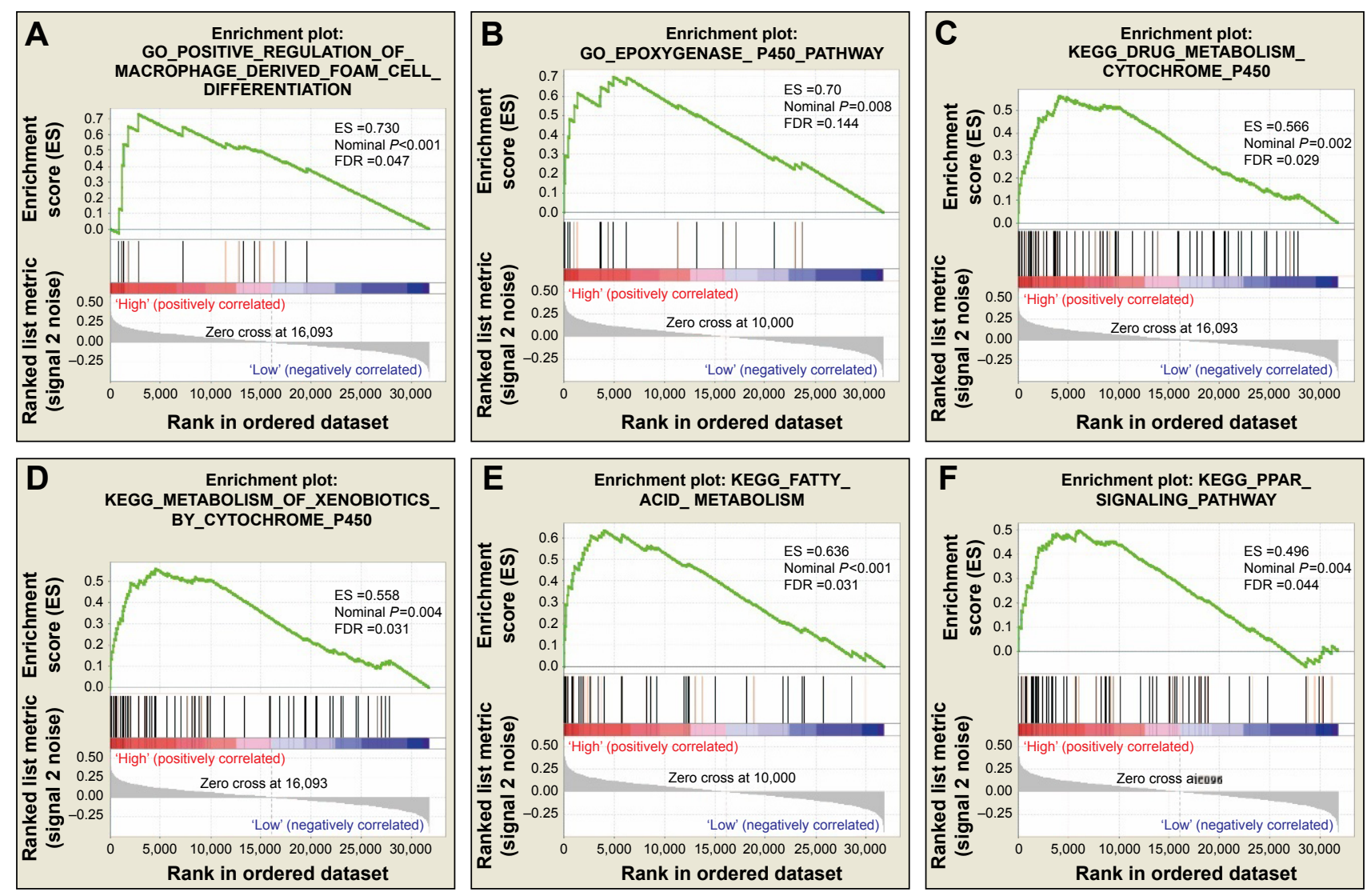

— Enrichment profile $\quad-$ Hits - Ranking metric scores

Figure 5 GSEA results of $A D H I A$ expressed in PAAD patients.

Notes: (A and B) GSEA results of c5 reference gene sets for high ADHIA expression groups; (C-F) GSEA results of c2 reference gene sets for high ADHIA expression groups.

Abbreviations: $A D H$, alcohol dehydrogenase; ES, enrichment score; FDR, false discovery rate; GSEA, gene set enrichment analysis; PAAD, pancreatic adenocarcinoma.

kinase (MAPK), and the pancreatic cancer signaling pathway (Figure 6F-L; Table S5). We also investigated the potential mechanism in $A D H 6$ and demonstrated that high $A D H 6$ expression was related to primary alcohol metabolic processes (Figure 7A; Table S6), fatty acid and retinol metabolism, and drug metabolism cytochrome $\mathrm{P} 450$ (Figure 7B-F; Table S7).

\section{Discussion}

Ethanol is first metabolized by ADH isoenzymes and then the resulting product is further metabolized by aldehyde dehydrogenase (ALDH) isoenzymes into acetic acid. ${ }^{16}$ The disproportion between ADH and ALDH may lead to an increased ability for ethanol oxidation and less capability to remove acetaldehyde, resulting in deleterious alcohol metabolites accumulating in vivo, which may subsequently cause oncogenesis. ${ }^{17} \mathrm{ADH}$ isoenzymes are divided into several classes on the basis of differences in biological characteristics. ${ }^{18}$ Isoenzymes of class I ADH are encoded by $A D H 1 A, A D H 1 B$, and $A D H 1 C$, whereas class II, III, IV, and class $\mathrm{V} A D H$ are encoded by $A D H 4, A D H 5, A D H 6$, and $A D H 7$, respectively..$^{19}$ Numerous studies have shown that the serum levels of class I ADH are a potential diagnostic marker in multiple cancers, including renal cell, ${ }^{20}$ brain, ${ }^{21}$ colorectal, ${ }^{22}$ endometrial, ${ }^{23}$ and cervical cancers. ${ }^{24}$ Similar diagnostic values can also be observed in class III ADH for pancreatic cancer, ${ }^{8}$ and class IV ADH for esophagea ${ }^{25}$ and gastric cancers. ${ }^{26}$ The diagnostic values of ADH isoenzymes in other cancers have not yet been reported, but the difference of ADH isoenzymes between cancer patients and healthy subjects has already been observed. Both the serum and tissue expression level of class I and total ADH were significantly increased in liver, ${ }^{27,28}$ colorectal, ${ }^{29,30}$ and brain cancers, ${ }^{31,32}$ while ALDH levels were not statistically significant different between cancer patients and healthy subjects. The upregulation trend of class I ADH between 

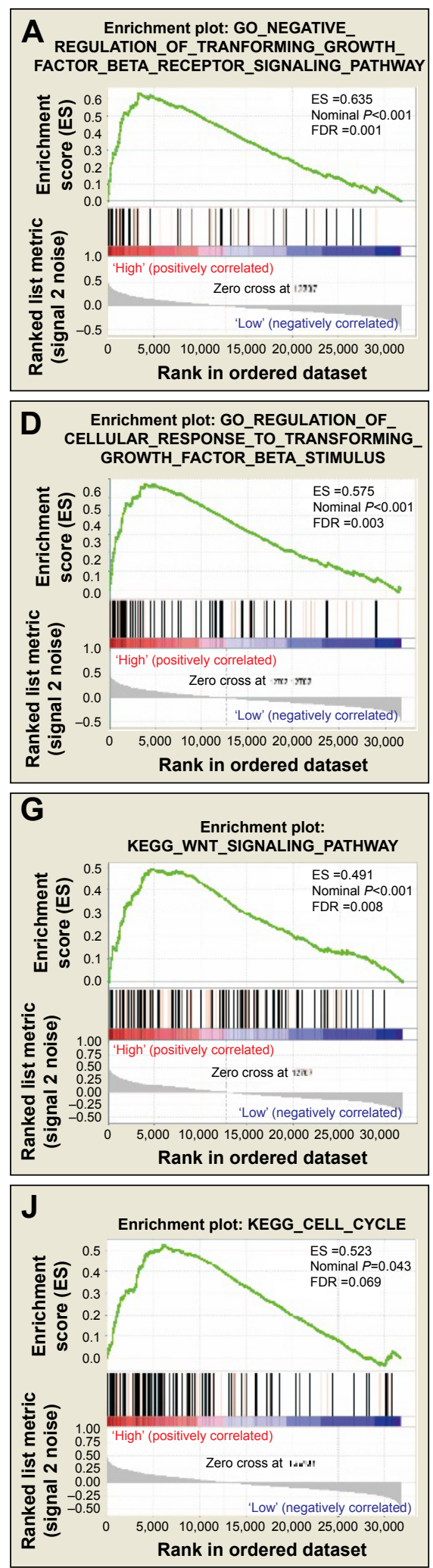
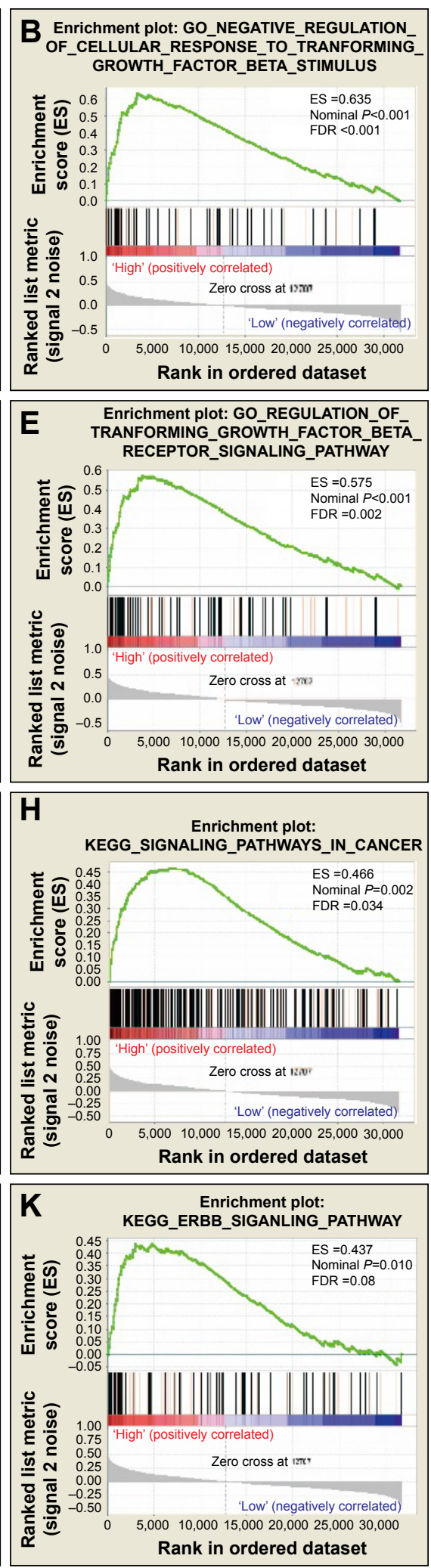

- Enrichment profile - Hits - Ranking metric scores
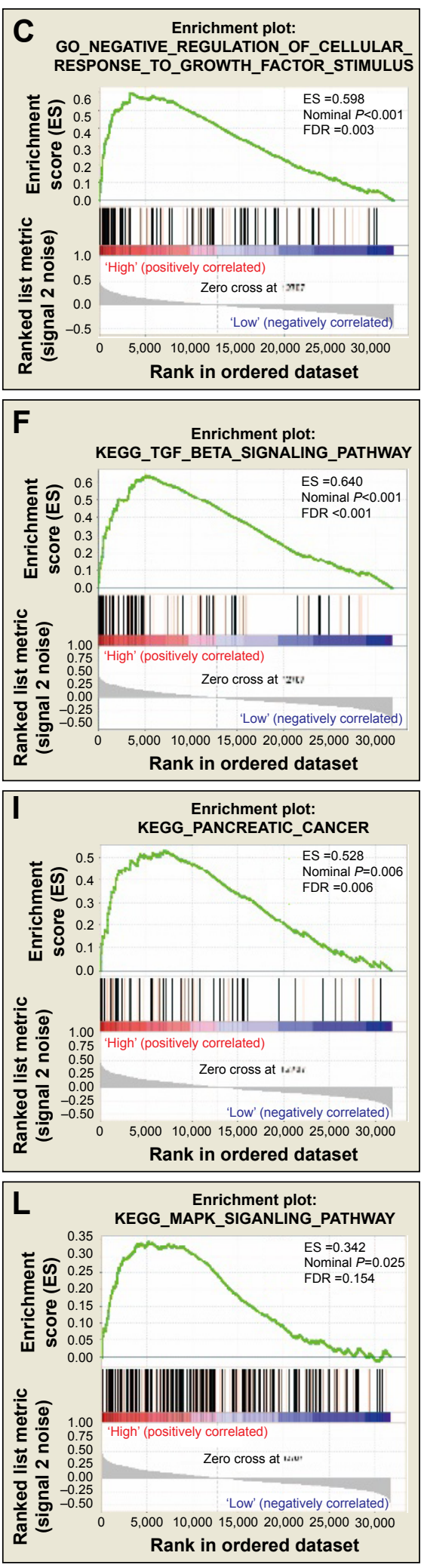

Figure 6 GSEA results of $A D H 5$ expressed in PAAD patients.

Notes: (A-E) GSEA results of c5 reference gene sets for high ADH5 expression groups; (F-L) GSEA results of $c 2$ reference gene sets for high ADH5 expression groups. Abbreviations: $A D H$, alcohol dehydrogenase; ES, enrichment score; FDR, false discovery rate; GSEA, gene set enrichment analysis; PAAD, pancreatic adenocarcinoma. 

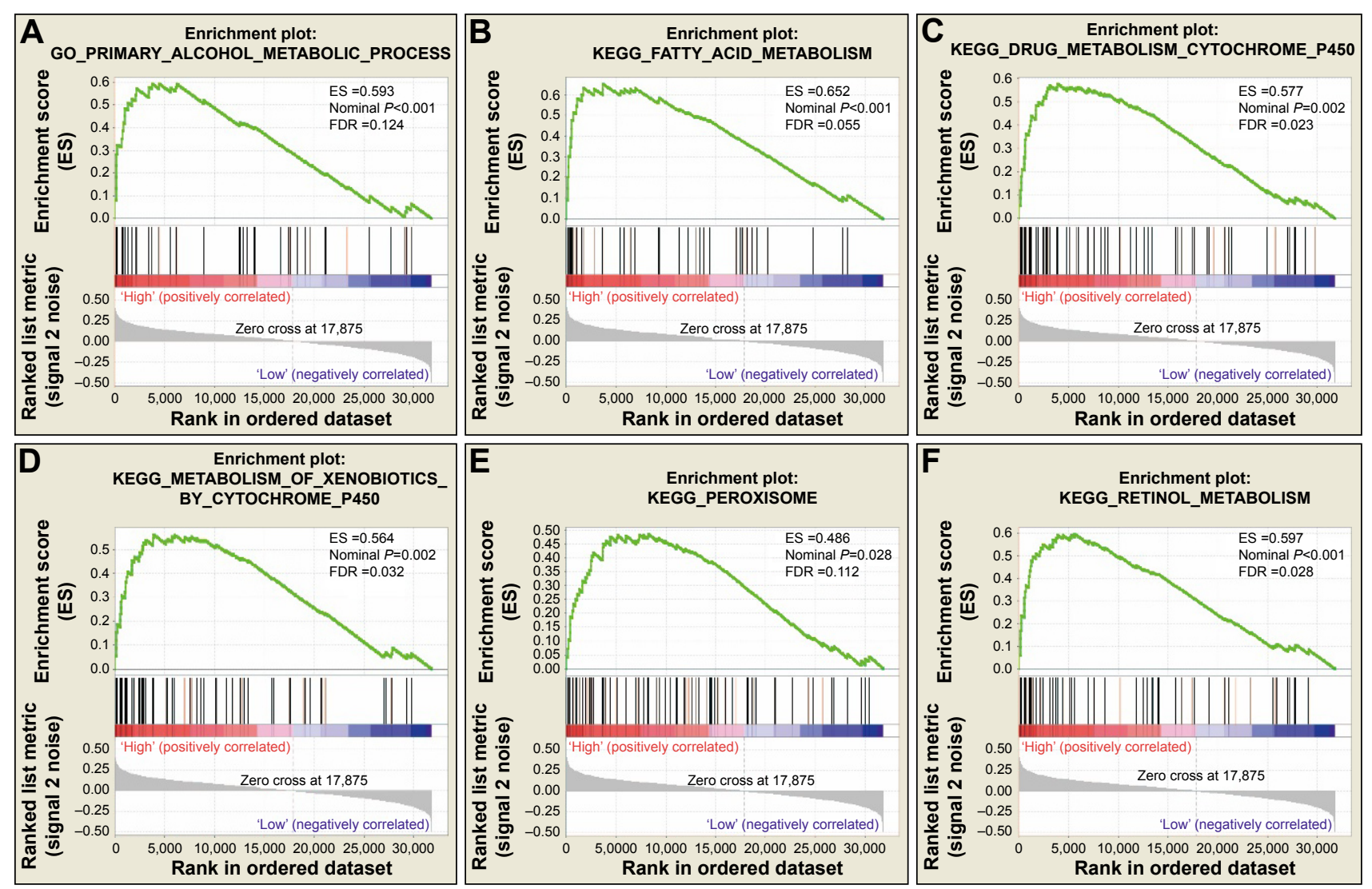

Enrichment profile - Hits _ Ranking metric scores

Figure 7 GSEA results of $A D H 6$ expressed in PAAD patients.

Notes: (A) GSEA results of c5 reference gene sets for high ADH6 expression groups; (B-F) GSEA results of c2 reference gene sets for high ADH6 expression groups. Abbreviations: ADH, alcohol dehydrogenase; ES, enrichment score; FDR, false discovery rate; GSEA, gene set enrichment analysis; PAAD, pancreatic adenocarcinoma.

cancer and healthy tissue can also be found in cervical, ${ }^{33}$ ovarian, ${ }^{34}$ endometrial, ${ }^{35}$ and renal cell cancers, ${ }^{36}$ whereas the upregulation trend of class I ADH for cancer serum has been reported in bladder and esophageal cancers. ${ }^{37,38}$ However, the expression of class I ADH in breast cancer was significantly decreased compared to the tissue of healthy subjects, and the expression of ALDH was unchanged. ${ }^{39}$ An upregulation trend of class III and class IV ADH was also shown in pancreatic and esophageal tumor tissue, respectively. ${ }^{7,40}$ Besides the use of the differences of $\mathrm{ADH}$ isoenzymes expression for cancer diagnosis, the genetic variant of ADH can also change the susceptibility of cancer. Polymorphisms of $A D H 1 C$ are significantly associated with the risk of colorectal cancer, ${ }^{41}$ oral squamous cell carcinoma, ${ }^{42,43}$ bladder cancer, ${ }^{44}$ upper aerodigestive tract cancers, ${ }^{45,46}$ head and neck squamous cell carcinoma, ${ }^{47}$ and gastric cancer. ${ }^{48,49}$

Despite numerous reports of $\mathrm{ADH}$ isoenzyme diagnosis values and cancer susceptibility, the prognostic value of $\mathrm{ADH}$ genes has rarely been investigated. A previous study by Wei et al indicated that $\mathrm{ADH} 4$ may act as a potential prognostic marker for hepatocellular carcinoma (HCC), and lower expression of ADH4 may be associated with a worse survival. ${ }^{50}$ Our previous study on hepatitis B virus (HBV)related $\mathrm{HCC}$ also demonstrates that the upregulation of $A D H 1 A, A D H 1 C$, and ADH6 in HCC tumor tissues was associated with favorable prognosis, whereas high $A D H 1 C$ and $A D H 5$ reduced the risk of tumor recurrence in HBV-related $\mathrm{HCC}$, respectively. ${ }^{51}$ In the current study, our results indicate that a high expression of $A D H 1 A$ and $A D H 6$ has a protective effect in PAAD prognosis, while a high expression of $A D H 5$ may increase the risk of death. In addition, the combination of these three $\mathrm{ADH}$ genes has prediction values for PAAD prognosis, and the prognosis difference between different combination groups was significant. Our findings imply that individuals of these three ADH genes may serve as a PAAD prognostic marker; however, their combination showed a strong interaction and better predictive value for PAAD prognosis. Once validated, ADH genes may be valuable biomarkers in PAAD diagnosis and prognostic prediction, and later these biomarkers may be used in combination with 
other clinical diagnosis and prognostic factors for decisionmaking in PAAD management.

To investigate the potential mechanism of ADH genes in PAAD prognosis, we used a genome-wide RNA sequencing dataset in GSEA and substantiated that both $A D H 1 A$ and ADH6 were involved in drug metabolism cytochrome $\mathrm{P} 450$ and fatty acid metabolism pathways. Human cytochrome P450 (CYP) enzymes are mainly distributed in the smooth endoplasmic reticulum and involved in detoxification through the metabolism of toxic fat-soluble substances to water-soluble substances, which are then excreted. ${ }^{52}$ P450 enzymes play a key role in cancer formation and cancer treatment, and mediate the metabolic activation of anticancer drugs and precarcinogens, as well as anticancer drug inactivation. ${ }^{53}$ An in vitro study has substantiated that the expression of CYP2B1 enzymes (retrovirus-mediated transduction) leads to an increased susceptibility to ifosfamide in pancreatic cancer. ${ }^{54}$ Studies suggest that P450 enzymes have the potential to be used as distinguishing markers in pancreatic pathology and targets of pancreatic cancer gene therapy. ${ }^{55,56}$ On the basis of GSEA results, we deduced that both $A D H 1 A$ and a high expression of $A D H 6$ were involved in the P450-related pathway and biological processes that are associated with the progress and treatment of pancreatic cancer, and may play a role in OS of PAAD via $\mathrm{P} 450$.

TGF- $\beta$ regulation-related pathways and biological processes, Wnt, the cell cycle, ErbB, and the MAPK signaling pathway were significantly enriched in the ADH5 highexpression group. TGF- $\beta$ family members participate in multiple cellular functions such as proliferation, apoptosis, differentiation, and migration. Research by Friess et al substantiated that an enhanced expression of TGF- $\beta$ isoforms in pancreatic cancer was correlated with a worse survival, ${ }^{57}$ while a study by Glazer et al demonstrated that patients with early-stage pancreatic cancer have longer median survival with TGF $\beta 1$ overexpression. ${ }^{58}$ In addition, studies have reported that the TGF- $\beta$ pathway may serve as a potential target for targeted therapy ${ }^{59,60}$ and the inhibition of the TGF pathway can decrease PAAD growth and invasiveness. ${ }^{61}$ These findings suggest that high ADH5 expression may influence TGF- $\beta$ regulation-related pathways and biological processes, and, therefore, may play a role in PAAD prognosis.

The Wnt signaling pathway plays an important role in physiological and pathological processes including the occurrence and development of tumors. Activation of the Wnt/ $\beta$-catenin signaling pathway may enhance pancreatic cancer development ${ }^{62}$ and increase pancreatic cancer tumorigenicity via miR-744. ${ }^{63}$ Moreover, Jiang et al indicated that Wnt2 expression in pancreatic cancer tissues was significantly associated with tumor development by activation of the Wnt pathways and serves as a potential candidate for targeted therapy of pancreatic cancer. ${ }^{64}$ The ErbB signaling pathway functions through ErbB family members (including ErbB-1, ErbB-2, ErbB-3, and ErbB-4) and the MAPK pathway is a common downstream target of all ErbB receptors. Previous studies indicate that ErbB-1 and ErbB-3 play an important role in pancreatic cancer and may serve as a potential candidate for targeted therapy of pancreatic cancer. ${ }^{65-67}$ Furthermore, Koizumi et al revealed that it is necessary for p38 MAPK signaling activation in gemcitabine-induced cell death in pancreatic cancer, and conclude that $\mathrm{p} 38$ MAPK signaling pathways could serve as a novel target for gemcitabine-based therapy. ${ }^{68}$ In summary, the potential mechanism of high ADH5 expression in PAAD prognosis is probably because it is involved in multiple biological processes and signaling pathways that are related to pancreatic cancer development, the cell cycle, targeted therapy, and survival.

There were some limitations to our study that need to be recognized. First, the clinical information from the TCGA database was not comprehensive, and the information for PAAD patients from the TCGA, such as tumor size, histology, lymphatic invasion, venous invasion, and treatment, was not available on the TCGA website. Therefore, our study evaluated the association between ADH gene expression and OS on the basis of multivariate survival analysis that was only adjusted for alcohol history and tumor stage in a Cox proportional hazards regression model. Second, only four PAAD adjacent normal tissues expression data are available in TCGA, and this resulted in a test with low power. Therefore, further investigations of ADH gene distribution between tumors and adjacent normal tissues are needed. Third, our current study based on the TCGA database to analyze the prognosis prediction of the mRNA expression level of ADH isozymes lacks verification at protein level. Therefore, future research is still needed to address these issues.

Despite these limitations, ours is the first study to investigate the association between individual $\mathrm{ADH}$ gene expression and OS in PAAD patients, as well as the joint effects of prognostic values among three ADH genes. We also investigated the potential mechanism of $\mathrm{ADH}$ genes in PAAD prognostics using the GSEA approach. These findings provide insight into $\mathrm{ADH}$ genes in cancer clinical outcomes and may have clinical utility for prognosis prediction and decision-making in PAAD management. 


\section{Conclusion}

Our data suggest that $A D H 1 A, A D H 5$, and $A D H 6$ may be potential prognostic biomarkers of PAAD, and their combination showed a strong interaction and better predictive value for PAAD prognosis. The potential mechanism of $A D H 1 A$ and $A D H 6$ in PAAD prognosis was that a high expression of $A D H 1 A$ and $A D H 6$ was involved in the $\mathrm{P} 450$-related pathway and biological processes, while high $A D H 5$ expression was involved in the TGF- $\beta$ regulationrelated pathway and biological processes, Wnt, the cell cycle, ErbB, and the MAPK signaling pathway. Functional experiments will be needed for the further validation of these findings in a future study. Due to the small sample size and incomplete clinical information in the current study, further well-designed and larger sample size studies are necessary to validate our results.

\section{Acknowledgments}

This work was supported in part by the National Nature Science Foundation of China (No: 81560535, 81072321, 30760243, 30460143 and 30560133), 2009 Program for New Century Excellent Talents in University (NCET), Guangxi Nature Sciences Foundation (No: GuiKeGong 1104003A-7), and Guangxi Health Ministry Medicine Grant (Key-Scientific Research-Grant Z201018). Self-raised Scientific Research Fund of the Health and Family Planning Commission of Guangxi Zhuang Autonomous Region (Z2016318). The authors thank Dr Ketuan Huang, Tingdong Yu, Wei Qin, Chengkun Yang, Guangzhi Zhu, Hao Su, Xiangkun Wang, Zhengtao Liu, and Prof Lequn Li, Xue Qin, Liming Shang, Xinping Ye, Bin Chen, Kaiyin Xiao, Minhao Peng, Zhen Liu, and Sicong $\mathrm{Lu}$ for their contribution on manuscript revision. Thanks also go to the contributors of the Cancer Genome Atlas for sharing the PAAD RNA sequencing dataset on open access. In addition, we also would like to acknowledge the helpful comments that our reviewers provided to this paper.

\section{Disclosure}

The authors report no conflicts of interest in this work.

\section{References}

1. Kamisawa T, Wood LD, Itoi T, Takaori K. Pancreatic cancer. Lancet. 2016;388(10039):73-85.

2. Torre LA, Bray F, Siegel RL, Ferlay J, Lortet-Tieulent J, Jemal A. Global cancer statistics, 2012. CA Cancer J Clin. 2015;65(2):87-108.

3. Chen W, Zheng R, Baade PD, et al. Cancer statistics in China, 2015. CA Cancer J Clin. 2016;66(2):115-132.

4. Zeng H, Zheng R, Guo Y, et al. Cancer survival in China, 2003-2005: a population-based study. Int J Cancer. 2015;136(8):1921-1930.

5. Haber PS, Apte MV, Applegate TL, et al. Metabolism of ethanol by rat pancreatic acinar cells. J Lab Clin Med. 1998;132(4):294-302.
6. Chrostek L, Jelski W, Szmitkowski M, Puchalski Z. Alcohol dehydrogenase $(\mathrm{ADH})$ isoenzymes and aldehyde dehydrogenase (ALDH) activity in the human pancreas. Dig Dis Sci. 2003;48(7):1230-1233.

7. Jelski W, Chrostek L, Szmitkowski M. The activity of class I, II, III, and IV of alcohol dehydrogenase isoenzymes and aldehyde dehydrogenase in pancreatic cancer. Pancreas. 2007;35(2):142-146.

8. Jelski W, Kutylowska E, Laniewska-Dunaj M, Szmitkowski M. Alcohol dehydrogenase (ADH) and aldehyde dehydrogenase (ALDH) as candidates for tumor markers in patients with pancreatic cancer. J Gastrointestin Liver Dis. 2011;20(3):255-259.

9. Mohamed AA, Soliman H, Ismail M, et al. Evaluation of circulating $\mathrm{ADH}$ and MIC-1 as diagnostic markers in Egyptian patients with pancreatic cancer. Pancreatology. 2015;15(1):34-39.

10. Anders S, Huber W. Differential expression analysis for sequence count data. Genome Biol. 2010;11(10):R106.

11. Shaul YD, Yuan B, Thiru P, et al. MERAV: a tool for comparing gene expression across human tissues and cell types. Nucleic Acids Res. 2016; 44(D1):D560-D566.

12. Subramanian A, Tamayo P, Mootha VK, et al. Gene set enrichment analysis: a knowledge-based approach for interpreting genomewide expression profiles. Proc Natl Acad Sci U S A. 2005;102(43): $15545-15550$

13. Mootha VK, Lindgren CM, Eriksson KF, et al. PGC-1alpha-responsive genes involved in oxidative phosphorylation is coordinately downregulated in human diabetes. Nat Genet. 2003;34(3):267-273.

14. Reiner A, Yekutieli D, Benjamini Y. Identifying differentially expressed genes using false discovery rate controlling procedures. Bioinformatics. 2003;19(3):368-375.

15. Benjamini Y, Hochberg Y. Controlling the false discovery rate: a practical and powerful approach to multiple testing. J R Stat Soc Series B Stat Methodol. 1995;57(1):289-300.

16. Klyosov AA. Kinetics and specificity of human liver aldehyde dehydrogenases toward aliphatic, aromatic, and fused polycyclic aldehydes. Biochemistry. 1996;35(14):4457-4467.

17. Orywal K, Szmitkowski M. Alcohol dehydrogenase and aldehyde dehydrogenase in malignant neoplasms. Clin Exp Med. 2017;17(2): 131-139.

18. Holmes RS. Alcohol dehydrogenases: a family of isozymes with differential functions. Alcohol Alcohol Suppl. 1994;2:127-130.

19. Jelski W, Szmitkowski M. Alcohol dehydrogenase (ADH) and aldehyde dehydrogenase (ALDH) in the cancer diseases. Clin Chim Acta. 2008;395(1-2):1-5.

20. Orywal K, Jelski W, Werel T, Szmitkowski M. The diagnostic significance of serum alcohol dehydrogenase isoenzymes and aldehyde dehydrogenase activity in renal cell cancer patients. Exp Mol Pathol. 2016;100(3):416-420.

21. Jelski W, Laniewska-Dunaj M, Orywal K, Kochanowicz J, Rutkowski R, Szmitkowski M. The diagnostic value of alcohol dehydrogenase $(\mathrm{ADH})$ isoenzymes and aldehyde dehydrogenase (ALDH) measurement in the sera of patients with brain tumor. Arch Med Sci. 2017; 13(2):346-352.

22. Jelski W, Mroczko B, Szmitkowski M. The diagnostic value of alcohol dehydrogenase (ADH) isoenzymes and aldehyde dehydrogenase (ALDH) measurement in the sera of colorectal cancer patients. Dig Dis Sci. 2010;55(10):2953-2957.

23. Orywal K, Jelski W, Zdrodowski M, Szmitkowski M. The diagnostic value of alcohol dehydrogenase isoenzymes and aldehyde dehydrogenase measurement in the sera of patients with endometrial cancer. Anticancer Res. 2013;33(9):3725-3730.

24. Orywal K, Jelski W, Zdrodowski M, Szmitkowski M. The diagnostic value of alcohol dehydrogenase isoenzymes and aldehyde dehydrogenase measurement sera of cervical cancer patients. Anticancer Res. 2016;36(5):2265-2269.

25. Jelski W, Laniewska-Dunaj M, Niklinski J, Kozlowski M, Laudanski J, Szmitkowski M. The alcohol dehydrogenase isoenzyme (ADH IV) as a candidate tumour marker of esophageal cancer. Acta Biochim Polonica. 2013;60(3):489-493. 
26. Jelski W, Orywal K, Laniewska M, Szmitkowski M. The diagnostic value of alcohol dehydrogenase $(\mathrm{ADH})$ isoenzymes and aldehyde dehydrogenase (ALDH) measurement in the sera of gastric cancer patients. Clin Exp Med. 2010;10(4):215-219.

27. Jelski W, Zalewski B, Szmitkowski M. Alcohol dehydrogenase (ADH) isoenzymes and aldehyde dehydrogenase (ALDH) activity in the sera of patients with liver cancer. J Clin Lab Anal. 2008;22(3):204-209.

28. Jelski W, Zalewski B, Szmitkowski M. The activity of class I, II, III, and IV alcohol dehydrogenase (ADH) isoenzymes and aldehyde dehydrogenase (ALDH) in liver cancer. Dig Dis Sci. 2008;53(9):2550-2555.

29. Jelski W, Zalewski B, Chrostek L, Szmitkowski M. Alcohol dehydrogenase $(\mathrm{ADH})$ isoenzymes and aldehyde dehydrogenase (ALDH) activity in the sera of patients with colorectal cancer. Clin Expl Med. 2007;7(4):154-157.

30. Jelski W, Zalewski B, Chrostek L, Szmitkowski M. The activity of class I, II, III, and IV alcohol dehydrogenase isoenzymes and aldehyde dehydrogenase in colorectal cancer. Dig Dis Sci. 2004;49(6):977-981.

31. Jelski W, Laniewska-Dunaj M, Orywal K, Kochanowicz J, Rutkowski R, Szmitkowski M. The activity of alcohol dehydrogenase (ADH) isoenzymes and aldehyde dehydrogenase (ALDH) in the sera of patients with brain cancer. Neurochem Res. 2014;39(12):2313-2318.

32. Laniewska-Dunaj M, Jelski W, Orywal K, Kochanowicz J, Rutkowski R, Szmitkowski M. The activity of class I, II, III and IV of alcohol dehydrogenase $(\mathrm{ADH})$ isoenzymes and aldehyde dehydrogenase (ALDH) in brain cancer. Neurochem Res. 2013;38(7):1517-1521.

33. Orywal K, Jelski W, Zdrodowski M, Szmitkowski M. The activity of class I, II, III and IV alcohol dehydrogenase isoenzymes and aldehyde dehydrogenase in cervical cancer. Clin Biochem. 2011;44(14-15): 1231-1234.

34. Orywal K, Jelski W, Zdrodowski M, Szmitkowski M. The activity of class I, II, III and IV alcohol dehydrogenase isoenzymes and aldehyde dehydrogenase in ovarian cancer and ovarian cysts. Adv Med Sci. 2013; 58(2):216-220.

35. Orywal K, Jelski W, Zdrodowski M, Szmitkowski M. The activity of class I, II, III, and IV alcohol dehydrogenase isoenzymes and aldehyde dehydrogenase in endometrial cancer. J Clin Lab Anal. 2010;24(5): 334-339.

36. Orywal K, Jelski W, Werel T, Szmitkowski M. The activity of class I, II, III and IV alcohol dehydrogenase isoenzymes and aldehyde dehydrogenase in renal cell carcinoma. Exp Mol Pathol. 2015;98(3): 403-406.

37. Orywal K, Jelski W, Werel T, Szmitkowski M. The activity of class I, II, III and IV alcohol dehydrogenase isoenzymes and aldehyde dehydrogenase in the sera of bladder cancer patients. Acta Biochim Polonica 2017;64(1):81-84.

38. Jelski W, Kozlowski M, Laudanski J, Niklinski J, Szmitkowski M. Alcohol dehydrogenase isoenzymes and aldehyde dehydrogenase activity in the sera of patients with esophageal cancer. Clin Exp Med. 2009;9(2):131-137.

39. Jelski W, Chrostek L, Szmitkowski M, Markiewicz W. The activity of class I, II, III and IV alcohol dehydrogenase isoenzymes and aldehyde dehydrogenase in breast cancer. Clin Exp Med. 2006;6(2): 89-93.

40. Jelski W, Kozlowski M, Laudanski J, Niklinski J, Szmitkowski M. The activity of class I, II, III, and IV alcohol dehydrogenase (ADH) isoenzymes and aldehyde dehydrogenase (ALDH) in esophageal cancer. Dig Dis Sci. 2009;54(4):725-730.

41. Bongaerts BW, de Goeij AF, Wouters KA, et al. Alcohol consumption, alcohol dehydrogenase $1 \mathrm{C}$ (ADH1C) genotype, and risk of colorectal cancer in the Netherlands Cohort Study on diet and cancer. Alcohol. 2011;45(3):217-225.

42. Brocic M, Supic G, Zeljic K, et al. Genetic polymorphisms of ADH1C and CYP2E1 and risk of oral squamous cell carcinoma. Otolaryngol Head Neck Surg. 2011;145(4):586-593.

43. Solomon PR, Selvam GS, Shanmugam G. Polymorphism in ADH and MTHFR genes in oral squamous cell carcinoma of Indians. Oral Dis. 2008;14(7):633-639.
44. van Dijk B, van Houwelingen KP, Witjes JA, Schalken JA, Kiemeney LA. Alcohol dehydrogenase type 3 (ADH3) and the risk of bladder cancer. Eur Urol. 2001;40(5):509-514.

45. McKay JD, Truong T, Gaborieau V, et al. A genome-wide association study of upper aerodigestive tract cancers conducted within the INHANCE consortium. PLoS Genet. 2011;7(3):e1001333.

46. Oze I, Matsuo K, Suzuki T, et al. Impact of multiple alcohol dehydrogenase gene polymorphisms on risk of upper aerodigestive tract cancers in a Japanese population. Cancer Epidemiol Biomarkers Prev. 2009;18(11):3097-3102.

47. Ji YB, Lee SH, Kim KR, et al. Association between ADH1B and $\mathrm{ADH} 1 \mathrm{C}$ polymorphisms and the risk of head and neck squamous cell carcinoma. Tumour Biol. 2015;36(6):4387-4396.

48. Terry MB, Gammon MD, Zhang FF, et al. Alcohol dehydrogenase 3 and risk of esophageal and gastric adenocarcinomas. Cancer Causes Control. 2007;18(9):1039-1046.

49. Hidaka A, Sasazuki S, Matsuo K, et al; JPHC Study Group. Genetic polymorphisms of ADH1B, ADH1C and ALDH2, alcohol consumption, and the risk of gastric cancer: the Japan Public Health Center-based prospective study. Carcinogenesis. 2015;36(2):223-231.

50. Wei RR, Zhang MY, Rao HL, Pu HY, Zhang HZ, Wang HY. Identification of ADH4 as a novel and potential prognostic marker in hepatocellular carcinoma. Med Oncol. 2012;29(4):2737-2743.

51. Shang L, Zhu G, Su H, et al. Identification of alcohol dehydrogenase as a potential prognostic marker in HBV-related hepatocellular carcinoma. Int J Clin Exp Med. 2017;10(3):4457-4472.

52. Nebert DW, Russell DW. Clinical importance of the cytochromes P450. Lancet. 2002;360(9340):1155-1162.

53. Rodriguez-Antona $\mathrm{C}$, Ingelman-Sundberg M. Cytochrome $\mathrm{P} 450$ pharmacogenetics and cancer. Oncogene. 2006;25(11):1679-1691.

54. Hlavaty J, Petznek H, Holzmuller H, et al. Evaluation of a gene-directed enzyme-product therapy (GDEPT) in human pancreatic tumor cells and their use as in vivo models for pancreatic cancer. PLoS One. 2012;7(7): e40611.

55. Liu SX, Xia ZS, Zhong YQ. Gene therapy in pancreatic cancer. World journal of gastroenterology. 2014;20(37):13343-13368.

56. Gandhi AV, Saxena S, Relles D, et al. Differential expression of cytochrome P450 omega-hydroxylase isoforms and their association with clinicopathological features in pancreatic ductal adenocarcinoma. Ann Surg Oncol. 2013;20 (Suppl 3):S636-S643.

57. Friess H, Yamanaka Y, Buchler M, et al. Enhanced expression of transforming growth factor beta isoforms in pancreatic cancer correlates with decreased survival. Gastroenterology. 1993;105(6): 1846-1856.

58. Glazer ES, Welsh E, Pimiento JM, Teer JK, Malafa MP. TGFbeta1 overexpression is associated with improved survival and low tumor cell proliferation in patients with early-stage pancreatic ductal adenocarcinoma. Oncotarget. 2017;8(1):999-1006.

59. Craven KE, Gore J, Wilson JL, Korc M. Angiogenic gene signature in human pancreatic cancer correlates with TGF-beta and inflammatory transcriptomes. Oncotarget. 2016;7(1):323-341.

60. Javle M, Li Y, Tan D, et al. Biomarkers of TGF-beta signaling pathway and prognosis of pancreatic cancer. PLoS One. 2014;9(1): e85942.

61. Gaspar NJ, Li L, Kapoun AM, et al. Inhibition of transforming growth factor beta signaling reduces pancreatic adenocarcinoma growth and invasiveness. Mol Pharmacol. 2007;72(1):152-161.

62. Sano M, Driscoll DR, DeJesus-Monge WE, et al. Activation of WNT/ beta-catenin signaling enhances pancreatic cancer development and the malignant potential via up-regulation of Cyr61. Neoplasia. 2016; 18(12):785-794.

63. Zhou W, Li Y, Gou S, et al. MiR-744 increases tumorigenicity of pancreatic cancer by activating Wnt/beta-catenin pathway. Oncotarget. 2015;6(35):37557-37569.

64. Jiang H, Li Q, He C, et al. Activation of the Wnt pathway through Wnt2 promotes metastasis in pancreatic cancer. Am J Cancer Res. 2014;4(5): $537-544$. 
65. Thomas G, Chardes T, Gaborit N, et al. HER3 as biomarker and therapeutic target in pancreatic cancer: new insights in pertuzumab therapy in preclinical models. Oncotarget. 2014;5(16):7138-7148.

66. Troiani T, Martinelli E, Capasso A, et al. Targeting EGFR in pancreatic cancer treatment. Curr Drug Targets. 2012;13(6):802-810.

67. Miyabayashi K, Ijichi H, Mohri D, et al. Erlotinib prolongs survival in pancreatic cancer by blocking gemcitabine-induced MAPK signals. Cancer Res. 2013;73(7):2221-2234.
68. Koizumi K, Tanno S, Nakano Y, et al. Activation of p38 mitogen-activated protein kinase is necessary for gemcitabine-induced cytotoxicity in human pancreatic cancer cells. Anticancer Res. 2005;25(5):3347-3353.

\section{Publish your work in this journal}

OncoTargets and Therapy is an international, peer-reviewed, open access journal focusing on the pathological basis of all cancers, potential targets for therapy and treatment protocols employed to improve the management of cancer patients. The journal also focuses on the impact of management programs and new therapeutic agents and protocols on

\section{Dovepress}

patient perspectives such as quality of life, adherence and satisfaction. The manuscript management system is completely online and includes a very quick and fair peer-review system, which is all easy to use. Visit http://www.dovepress.com/testimonials.php to read real quotes from published authors. 